\title{
Linear multivariate evaluation models for spatial perception of soundscape
}

\author{
Zhiyong Denga) \\ Music College, Capital Normal University, Beijing China \\ Jian Kang \\ School of Architecture, University of Sheffield, Sheffield, United Kingdom \\ Daiwei Wang \\ Music College, Capital Normal University, Beijing China \\ Aili Liu \\ College of Resource Environment and Tourism, Capital Normal University, Beijing, China \\ Joe Zhengyu Kang \\ The Queen's College, University of Oxford, Oxford, United Kingdom
}

(Received 30 April 2015; revised 25 September 2015; accepted 3 October 2015; published online 9 November 2015)

Soundscape is a sound environment that emphasizes the awareness of auditory perception and social or cultural understandings. The case of spatial perception is significant to soundscape. However, previous studies on the auditory spatial perception of the soundscape environment have been limited. Based on 21 native binaural-recorded soundscape samples and a set of auditory experiments for subjective spatial perception (SSP), a study of the analysis among semantic parameters, the inter-aural-cross-correlation coefficient (IACC), A-weighted-equal sound-pressure-level $\left(L_{\mathrm{eq}}\right)$, dynamic $(D)$, and SSP is introduced to verify the independent effect of each parameter and to re-determine some of their possible relationships. The results show that the more noisiness the audience perceived, the worse spatial awareness they received, while the closer and more directional the sound source image variations, dynamics, and numbers of sound sources in the soundscape are, the better the spatial awareness would be. Thus, the sensations of roughness, sound intensity, transient dynamic, and the values of $L_{\mathrm{eq}}$ and IACC have a suitable range for better spatial perception. A better spatial awareness seems to promote the preference slightly for the audience. Finally, setting SSPs as functions of the semantic parameters and $L_{\mathrm{eq}}-D$-IACC, two linear multivariate evaluation models of subjective spatial perception are proposed. (C) 2015 Acoustical Society of America.

[http://dx.doi.org/10.1121/1.4934272]

$[\mathrm{NX}]$

Pages: $2860-2870$

\section{INTRODUCTION}

Soundscape, which was previously proposed by Canadian composer and ecologist Schafer in the 1970s, is a sound environment that emphasizes human awareness of their auditory perceptions or social and cultural understandings. Soundscape, as defined by Schafer, includes three main factors: audience, environment, and a sound event with the features of keynote, sound signal, and soundmark. ${ }^{1}$

In the case of human awareness, sound spatial perceptions are defined as a general auditory awareness of the three-dimensional sound spaces, locations and variations. ${ }^{2}$ Because soundscape cannot be isolated from the landscape, ${ }^{3,4}$ it is always significant to soundscape. During the 1950s, inter-aural level difference (ILD) and inter-aural time difference (ITD) were mechanisms for sound localizations, ${ }^{5,6}$ and then binaural impulse response was proposed by Schroeder ${ }^{7}$ to examine the sound quality of room acoustics.

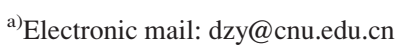

With the development of binaural recording technology, the inter-aural cross-correlation coefficient (IACC) was suggested as an independent acoustic parameter to evaluate sound spatial perceptions of a concert hall, ${ }^{2}$ and some relationships between room acoustics and psychoacoustics were found based on further study of the IACC. ${ }^{8,9}$ Around 2000, still based on the IACC, a model of the auditory brain system proposed by Ando was suggested to describe the primitive temporal and spatial factors for some spatial sensations, such as localization in the horizontal plane of sound fields. ${ }^{10-12}$ Recently, the head-related transfer function (HRTF) and inter-aural cross-correlation function (IACF) were used to create the spatial awareness of virtual audio environments and sound playback systems. ${ }^{13-15}$ However, previous studies on sound spatial perception of open space and soundscape environments were limited, and few efficient predictive models were introduced. According to some of the newest studies regarding the spatiotemporal variability of soundscapes, ${ }^{16}$ soundwalk, ${ }^{17}$ listening behaviors in public space $^{18,19}$ and the evaluations of acoustic and cultural 
awareness for historical soundscape environments, ${ }^{20-22}$ physical acoustic parameters alone, such as A-weighted equal sound pressure level $\left(L_{\mathrm{eq}}\right)$, IACC, or dynamic $(D)$ defined as the maximum difference of sound pressure level during the amplitude variations of a sound signal, ${ }^{21}$ are not efficient for predicting a more complicated spatial perception of the soundscape or real urban and rural public sound space.

Thus, based on 21 typical native binaural-recorded soundscape samples and a set of auditory experiments for the subjective spatial perceptions, the aim of this study is to verify the independent effect on subjective spatial perceptions (SSPs) of semantic parameters and three well-known and simplemeasured acoustic parameters, IACC, $L_{\text {eq }}(\mathrm{dBA})$, and $D$ (dynamic); re-determine some of their possible relationships; and finally propose two linear multivariate evaluation models of subjective spatial perceptions, taking into account SSPs as functions of the semantic parameters and $L_{\mathrm{eq}}-D$-IACC.

\section{METHODS}

\section{A. Study areas and samples}

The study was conducted in the Guangxi Province in the southern China, which is an ethnically diverse region with many types of unique but typical soundscape ecologies and cultures. The 21 binaural-recorded soundscape samples were recorded at three different historical autonomous areas of Zhuang Nationality, as shown in Fig. 1, including the central areas of Liuzhou City, Longji Village of Longsheng County, and Mudu Village of Napo County. The descriptions of soundscape contents and original occurrence circumstances are listed in Table II, with their sound level envelopes shown in Fig. 2.

\section{B. Binaural recording technology}

The binaural-recorded signals typically come from two small omni-directional microphones, which are located in

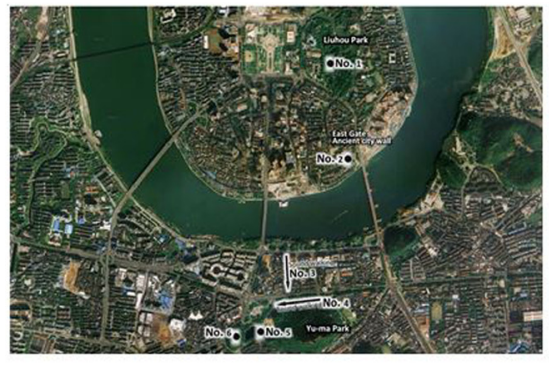

1a. Soundscape sample 1 - 6 from the central areas of Liuzhou City

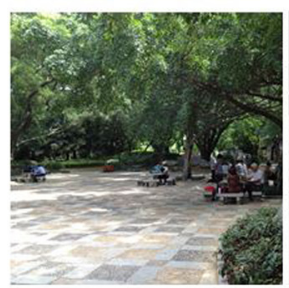

1d. Sample 1

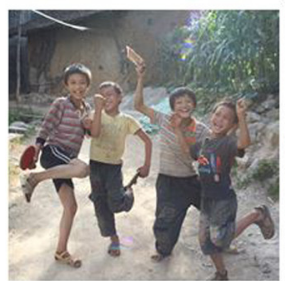

1j. Sample 7

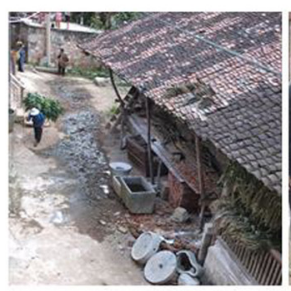

1p. Sample16

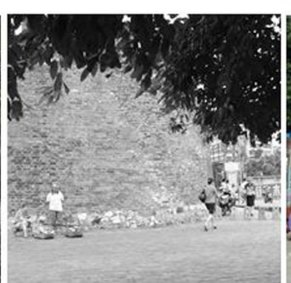

1e. Sample 2

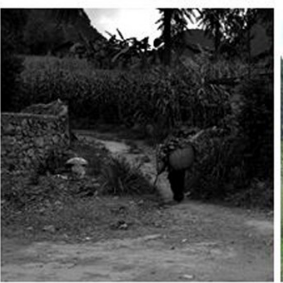

1k. Sample 8

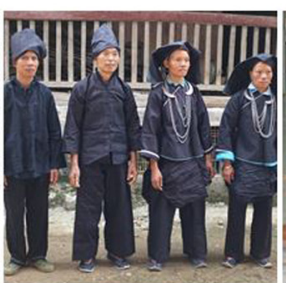

1q. Sample 17

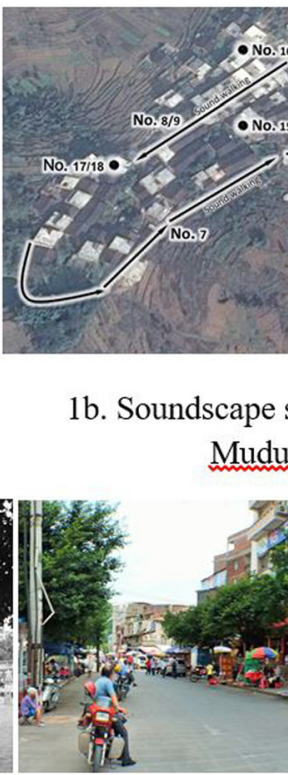

1f. Sample 3

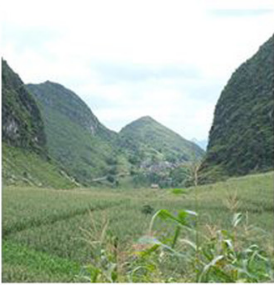

11. Sample $9 / 10$

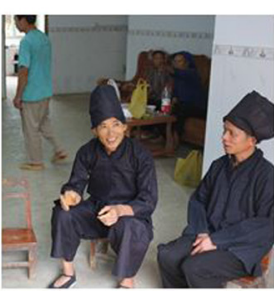

1r. Sample 18

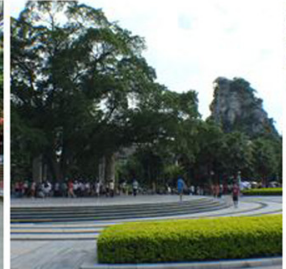

1g. Sample 4

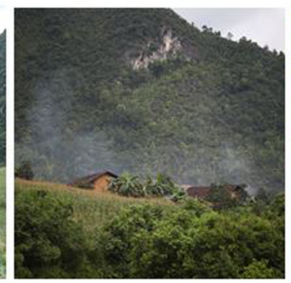

1m. Sample 11/15

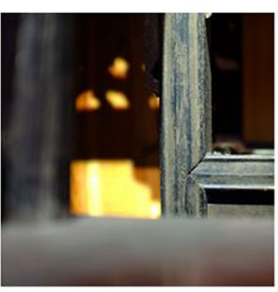

1s. Sample 19

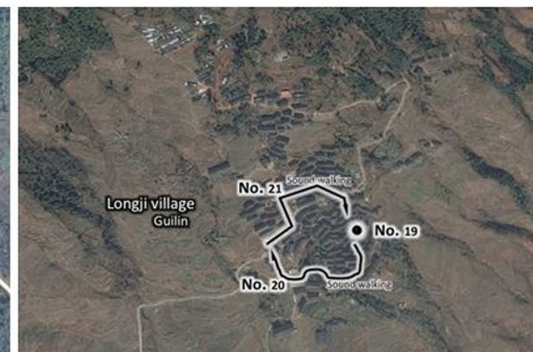

1c. Soundscape sample 19 - 21 from Longii Village

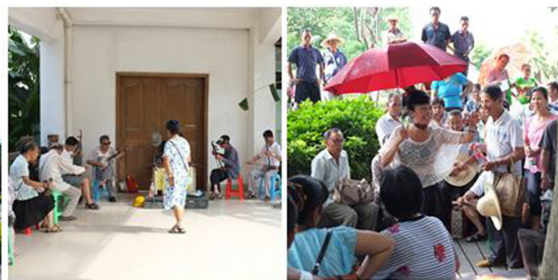

1h. Sample 5

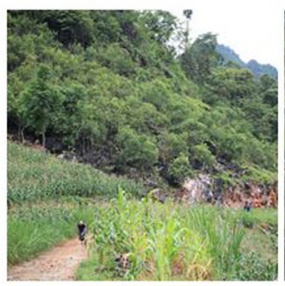

1n. Sample 12

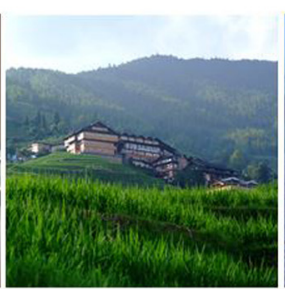

1t. Sample 20 1o. Sample $13 / 14$

1i. Sample 6
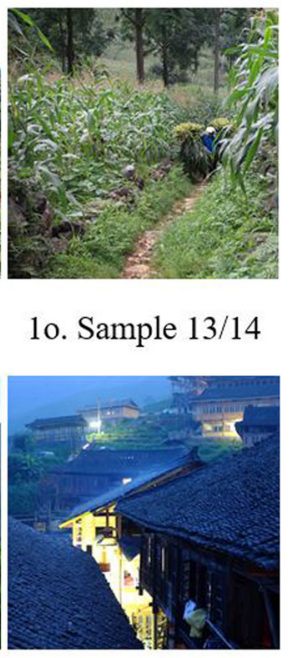

1u. Sample 21

FIG. 1. (Color online) The native locations and situations of 21 soundscape samples. 


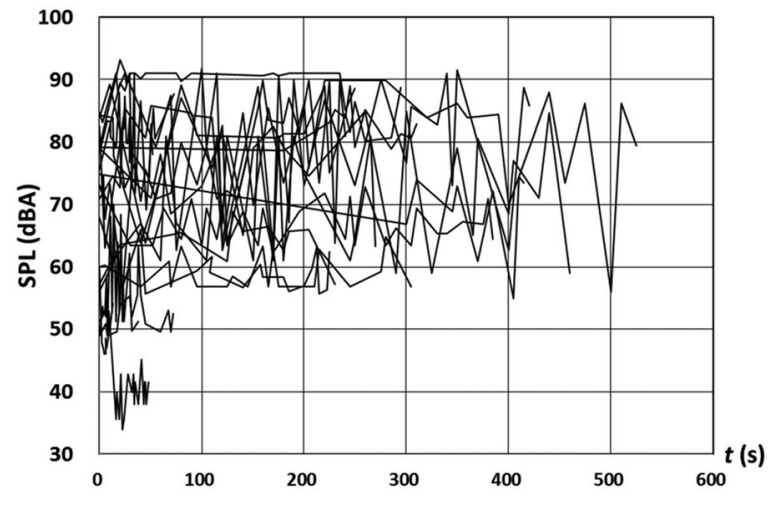

FIG. 2. Sound pressure level envelopes of 21 samples.

the ear canal of a human head or dummy head. When played through a pair of stereo earphones or headphones, a binaural-recorded sound signal could represent the spatial information around the head of the audience, mainly including the sound image locations and their variations with sound pressure level (SPL) variations. Binaural recording technology was previously used to examine the binaural impulse response of room acoustics. ${ }^{6}$ It is easy to acquire another important acoustic parameter, IACC, from binaural-recorded samples by using Eq. (1), while the IACF can be acquired as shown in Eq. (2).

All samples used in this paper were collected using binaural recording technology with the same real human head, and all samples were binaural sounds (3D sounds) based on the characteristics of the human auditory system. In order to avoid the effect on IACC evaluation from the movement of head, the positive axis of the human head was kept to a fixed direction as far as possible for stationary recorded samples, and for the sound walking samples, it was kept along with the forward direction of the walking path. The fixed directions of the stationary samples and walking paths of the sound walking samples were based on the situation of environment and the recommendation of local people. The "stationary" or "sound walking" status of each sample is listed in the last column of Table II.

In this paper, all of the binaural-recorded samples are digitized with a $44.1 \mathrm{kHz}$ sampling rate. Due to the possible maximum distance of the two eardrums, the delay time between the two eardrums is in the range of -44 samples to 44 samples because the aural sound images on the left and right hemispheres are approximately symmetric, especially in the middle frequency and low frequency. ${ }^{8}$ The delay time $\tau$, represented by the sample numbers, should be set in a range of 0 to 44 samples. Then, according to Eq. (2), the variegated IACF curves of the 21 samples are shown normally in Fig. 3:

$$
\begin{aligned}
& \mathrm{IACC}=\max \left|\mathrm{IACF}_{t_{1} t_{2}}(\tau)\right|, \\
& \mathrm{IACF}_{t_{1} t_{2}}(\tau)=\frac{\int_{t_{1}}^{t_{2}} p_{L}(t) p_{R}(t+\tau) d t}{\sqrt{\int_{t_{1}}^{t_{2}} p_{L}^{2}(t) d t \cdot \int_{t_{1}}^{t_{2}} p_{R}^{2}(t) d t}},
\end{aligned}
$$

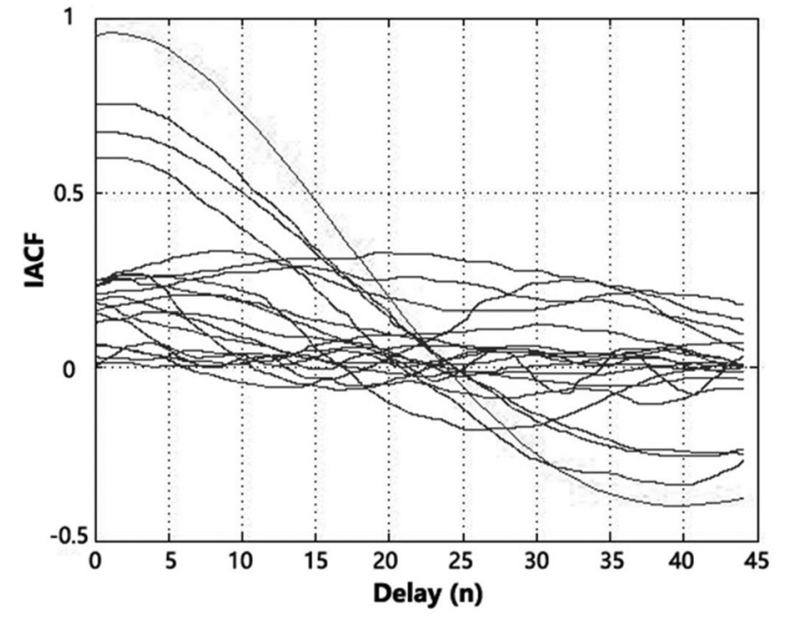

FIG. 3. IACF curves of 21 samples.

where $p_{L}$ is the sound pressure received by the left ear, represented by the voltage level of the left channel; $p_{R}$ is the sound pressure received by the right ear, represented by the voltage level of the right channel; $\tau$, is the delay time between two ears, represented by the sample numbers in a digitalized sound signal.

\section{Auditory experiment and semantic parameters}

To perceive the psychoacoustic sensations related to subjective spatial perceptions of normal people, an auditory experiment for all of the above 21 samples based on the semantic differential method ${ }^{23}$ was designed in this study. Twelve male and 12 female non-local subjects with normal hearing ability and from 20 to $40 \mathrm{yr}$ old were asked to complete a semantic measurement questionnaire with a 5-point Likert scale of the 11 pairs of semantic parameters, as shown in Table I. All of the subjects were well trained to understand the correct meanings of all semantic pairs.

All samples were binaural-recorded sounds and played back through a standard stereo headphone system with sound pressure levels consistent with the values of $L_{\mathrm{eq}}$ in Table II and an interval of $10 \mathrm{~s}$ between each sound. The duration of each soundscape sample was from 26 to 239 s.

\section{Statistical analysis}

Pearson correlation analysis was used to examine the possible relationships among the semantic parameters, IACC, $L_{\mathrm{eq}}$ (dBA), $D$ (dynamic), and the SSP. Then, the SSP was set as the controlling variable, and principal components analysis and system clustering analysis were applied to determine the interaction influence of $\mathrm{QN}, \mathrm{BL}, \mathrm{RS}, \mathrm{DO}$, CF, WS, SIV, TrD, NSS, and SPA, as well as to find the orthogonal principal components of the SSP. Finally, multiregression was used to create the linear single-value evaluation models of the SSP. All of the statistics mentioned above were carried out in MATLAB ${ }^{\circledR} 2012 \mathrm{a}$, SPSS $^{\circledR} 20.0$ and Excel ${ }^{\circledR}$ 2013. 


\begin{tabular}{|c|c|c|c|c|c|c|}
\hline \multirow[b]{2}{*}{ No. } & \multirow[b]{2}{*}{ Semantic parameter and code } & \multicolumn{5}{|c|}{ 5-point Likert scale } \\
\hline & & -2 & -1 & 0 & 1 & 2 \\
\hline \multirow[t]{11}{*}{1} & QN (Quiet-Noisy) & & & & & \\
\hline & BL (Boring-Lively) & & & & & \\
\hline & RS (Rough-Smooth) & & & & & \\
\hline & DO (Directive-Omni) & & & & & \\
\hline & CF (Close-Far) & & & & & \\
\hline & WS (Weak-Strong) & & & & & \\
\hline & SIV (Sound image variation, Less-More) & & & & & \\
\hline & TrD (Transient Dynamic, Low-High) & & & & & \\
\hline & NSS (Number of sound sources, Less-More) & & & & & \\
\hline & SPA (Subjective preferred assessment, Don't like-Like) & & & & & \\
\hline & SSP (Subjective spatial perceptions, Low-High) & & & & & \\
\hline
\end{tabular}

\section{RESULTS, ANALYSIS, AND MODELS}

\section{A. Correlation analysis}

According to the results of the auditory experiment, the average values of the semantic parameters (QN, BL, RS, DO, CF, WS, SIV, NSS, SPA, and the SSP), IACC, $L_{\mathrm{eq}}$, and descriptions of the soundscape contents are shown in Table II. The correlations are shown in Table III.

Generally, the sensation of sound directivity (DO) has the highest correlation with the SSP, with a negative coefficient of -0.660 , while the sensation of sound distance (CF) also has an approximate negative correlation but with a smaller absolute value of the coefficient of -0.252 . The sensations of sound source image variations and numbers (SIV and NSS) have a positive correlation with the SSP, with coefficients of 0.552 and 0.561 , respectively. The sensations of sound intensity (QN with a coefficient of 0.355 , WS with a coefficient of 0.316 , and $\operatorname{TrD}$ with a coefficient of 0.373 ) have weaker but detectable positive correlations, while the sensation of roughness (RS) has a weaker but negative correlation of -0.348 . Finally, the overall sensation of preference (BL and SPA) has the lowest correlation with the SSP, i.e., 0.019 and 0.006 , respectively, which are close to zero. Moreover, in the cases of the three important acoustic parameters, i.e., IACC, $L_{\mathrm{eq}}$, and $D$ (dynamic), the highest correlation value (i.e., 0.621) exists between $D$ (dynamic)

TABLE II. Semantic and acoustic parameter values of the soundscape samples.

\begin{tabular}{|c|c|c|c|c|c|c|c|c|c|c|c|c|c|c|c|c|}
\hline \multirow[b]{2}{*}{ No. } & \multicolumn{11}{|c|}{ Average value of semantic parameters } & \multicolumn{3}{|c|}{ Acoustic parameters } & \multirow[b]{2}{*}{$\begin{array}{l}\text { Soundscape } \\
\text { description }\end{array}$} & \multirow[b]{2}{*}{$\begin{array}{c}\text { Status of recorded } \\
\text { position }\end{array}$} \\
\hline & QN & $\mathrm{BL}$ & RS & DO & $\mathrm{CF}$ & WS & SIV & $\operatorname{TrD}$ & NSS & SPA & SSP & IACC & $\begin{array}{c}L_{\mathrm{eq}} \\
(\mathrm{dBA})\end{array}$ & $\begin{array}{c}D \\
(\mathrm{~dB})\end{array}$ & & \\
\hline 1 & 0.54 & 0.92 & 0.00 & -0.29 & 0.00 & -0.21 & 1.29 & 0.17 & 0.71 & 0.75 & 0.75 & 0.22 & 65 & 37 & Tango in Liuhou Park & Stationary \\
\hline 2 & 1.46 & -0.63 & -0.83 & 0.33 & -0.83 & 0.88 & 0.29 & 0.83 & 0.63 & -0.83 & -0.83 & 0.18 & 65 & 33 & Elderly people activities & Stationary \\
\hline 3 & 1.67 & -0.33 & -0.50 & -0.42 & -0.71 & 0.88 & 0.96 & 0.71 & 0.71 & -0.38 & -0.38 & 0.09 & 73 & 26 & Guangming Road Market & Sound walking \\
\hline 4 & 1.38 & -0.21 & -0.29 & -0.33 & -0.79 & 0.88 & 0.79 & 0.58 & 0.21 & -0.46 & -0.46 & 0.31 & 74 & 27 & Yu-ma Park soundscape & Sound walking \\
\hline 5 & 0.79 & 0.29 & 0.08 & 0.17 & -1.04 & 0.83 & -0.21 & 0.50 & -0.04 & 0.00 & 0.00 & 0.26 & 85 & 5 & $\begin{array}{l}\text { Small folk orchestra } \\
\text { with vocal }\end{array}$ & Stationary \\
\hline 6 & 0.38 & 0.54 & 0.00 & -0.04 & -0.83 & 0.54 & 0.50 & 0.63 & 0.75 & 0.17 & 0.17 & 0.23 & 75 & 31 & Three antiphonal singing & Stationary \\
\hline 7 & -0.42 & 1.38 & 0.79 & -0.71 & -0.75 & 0.08 & 1.04 & 0.63 & 0.54 & 1.21 & 1.21 & 0.14 & 72 & 46 & Village dusk soundscape & Sound walking \\
\hline 8 & -1.17 & 0.54 & 0.63 & -0.33 & -0.17 & -0.71 & -0.21 & -0.25 & -0.50 & 0.13 & 0.13 & 0.27 & 55 & 36 & Village night soundscape & Sound walking \\
\hline 9 & -1.38 & 0.63 & 0.75 & -0.04 & -0.08 & -0.50 & 0.13 & -0.33 & 0.17 & 0.33 & 0.33 & 0.33 & 60 & 35 & Village morning, sound & Sound walking \\
\hline 10 & -1.71 & 0.67 & 1.13 & 1.00 & 0.79 & -1.29 & -1.04 & -0.96 & -0.33 & 0.54 & 0.54 & 0.05 & 40 & 11 & Village morning, quiet & Sound walking \\
\hline 11 & -1.38 & 0.46 & 0.71 & 0.54 & 0.50 & -0.92 & -1.04 & -0.71 & -0.58 & 0.29 & 0.29 & 0.04 & 48 & 9 & Village sound with insects & Stationary \\
\hline 12 & -0.88 & 0.42 & 0.25 & 0.04 & -0.67 & -0.63 & -0.38 & -0.29 & -0.25 & 0.25 & 0.25 & 0.12 & 55 & 25 & Village sound of working & Sound walking \\
\hline 13 & -1.21 & 0.17 & 0.25 & 0.25 & -0.67 & 0.13 & -0.25 & 0.46 & 0.25 & 0.54 & 0.54 & 0.96 & 75 & 46 & Talk among local people & Stationary \\
\hline 14 & -0.38 & 0.38 & 0.33 & 0.29 & -0.58 & -0.33 & -0.46 & 0.13 & -0.46 & 0.13 & 0.13 & 0.60 & 69 & 12 & Village sound in farmland & Sound walking \\
\hline 15 & -0.29 & 0.42 & -0.08 & 0.58 & -0.92 & 0.13 & -0.38 & 0.33 & 0.08 & 0.13 & 0.13 & 0.67 & 75 & 37 & Village sound with birds & Stationary \\
\hline 16 & 0.00 & 0.75 & 0.29 & 0.58 & -1.38 & 0.67 & 0.17 & 0.67 & -0.04 & 0.58 & 0.58 & 0.76 & 76 & 13 & $\begin{array}{l}\text { Village sound } \\
\text { with crowing }\end{array}$ & Sound walking \\
\hline 17 & 0.25 & 0.46 & 0.38 & 0.17 & -1.21 & 0.75 & -0.67 & 0.54 & -0.13 & 0.38 & 0.38 & 0.22 & 79 & 21 & Antiphonal singing & Stationary \\
\hline 18 & 0.75 & 0.33 & -0.29 & -0.50 & -1.42 & 1.04 & 0.63 & 0.63 & 0.75 & 0.04 & 0.04 & 0.15 & 70 & 52 & Interviews for the singers & Stationary \\
\hline 19 & -0.75 & -0.04 & 0.25 & -0.04 & 0.04 & -0.71 & -0.29 & -0.50 & -0.04 & -0.21 & -0.21 & 0.27 & 50 & 17 & $\begin{array}{l}\text { Village soundscape } \\
\text { indoors }\end{array}$ & Stationary \\
\hline 20 & 0.63 & -0.63 & -0.29 & 0.00 & -0.42 & 0.38 & 0.54 & 0.33 & 0.38 & -0.54 & -0.54 & 0.59 & 70 & 35 & Valley sound walking & Sound walking \\
\hline 21 & -0.67 & 0.58 & 0.13 & -0.29 & -0.50 & -0.04 & 0.21 & -0.08 & -0.04 & 0.42 & 0.42 & 0.05 & 57 & 33 & Village sound walking & Sound walking \\
\hline
\end{tabular}


TABLE III. Correlation coefficients among the subjective spatial perception parameters.

\begin{tabular}{|c|c|c|c|c|c|c|c|c|c|c|c|c|c|c|}
\hline Parameters & QN & $\mathrm{BL}$ & $\mathrm{RS}$ & DO & $\mathrm{CF}$ & WS & SIV & $\operatorname{TrD}$ & NSS & IACC & $L_{\mathrm{eq}}(\mathrm{dBA})$ & $D(\mathrm{~dB})$ & SPA & SSP \\
\hline NQ & 1 & & & & & & & & & & & & & \\
\hline $\mathrm{BL}$ & -0.517 & 1 & & & & & & & & & & & & \\
\hline RS & -0.857 & 0.714 & 1 & & & & & & & & & & & \\
\hline DO & -0.357 & -0.058 & 0.260 & 1 & & & & & & & & & & \\
\hline $\mathrm{CF}$ & -0.593 & 0.107 & 0.536 & 0.265 & 1 & & & & & & & & & \\
\hline WS & 0.861 & -0.370 & -0.744 & -0.314 & -0.854 & 1 & & & & & & & & \\
\hline SIV & 0.643 & -0.047 & -0.523 & -0.750 & -0.344 & 0.538 & 1 & & & & & & & \\
\hline $\operatorname{TrD}$ & 0.794 & -0.234 & -0.682 & -0.350 & -0.859 & 0.935 & 0.613 & 1 & & & & & & \\
\hline NSS & 0.656 & -0.181 & -0.620 & -0.504 & -0.394 & 0.631 & 0.832 & 0.674 & 1 & & & & & \\
\hline IACC & -0.071 & -0.129 & -0.088 & 0.301 & -0.310 & 0.161 & -0.067 & 0.295 & -0.039 & 1 & & & & \\
\hline$L_{\mathrm{eq}}(\mathrm{dBA})$ & 0.638 & -0.107 & -0.478 & -0.223 & -0.834 & 0.845 & 0.415 & 0.890 & 0.458 & 0.452 & 1 & & & \\
\hline$D(\mathrm{~dB})$ & 0.109 & 0.053 & -0.268 & -0.583 & -0.261 & 0.244 & 0.568 & 0.366 & 0.622 & 0.122 & 0.184 & 1 & & \\
\hline SPA & -0.564 & 0.939 & 0.721 & -0.010 & 0.130 & -0.370 & -0.062 & -0.212 & -0.150 & 0.018 & -0.079 & 0.106 & 1 & \\
\hline SSP & 0.355 & 0.006 & -0.348 & -0.660 & -0.252 & 0.316 & 0.552 & 0.373 & 0.561 & -0.193 & 0.205 & 0.621 & 0.019 & 1 \\
\hline
\end{tabular}

and SSP, while the other ones show a similarity for the absolute values of -0.193 and 0.205 .

\section{B. Independent effect}

\section{Independent effect of semantic parameter}

Based on the 5-point Likert scale, an analysis with standard deviations for the variations of the SSP against the semantic parameters is shown in Fig. 4. According to the linked curves of the average values of the SSP, the independent effect of a semantic parameter can be interpreted in more detail.

Figure 4(a) shows an overall decline in relations between the sensation of noisiness (represented by QN, one of the parameters related to the sensation of sound intensity) and the SSP. Namely, the more noise the audience hears, the worse their perceived spatial awareness becomes. According to Figs. 4(d) and 4(e), the sensations of sound directivity (DO) and sound distance (CF) have similar monotonically decreasing relationships with the SSP. It is interesting to note that a close soundscape could result in a relatively high spatial perception, while it is easy to understand that directive sounds could create a more spatial sound environment. As shown in Fig. 4(b), there is also a monotonically decreasing but weaker relationship between the parameters BL and SSP.

In contrast, Figs. 4(g), 4(i), and 4(j) give the overall increasing relationships among the sensations of sound source image variations (SIV), numbers of sound sources (NSS), and subjective preferred assessment (SPA) and the SSP, which means that more variations and numbers of sound sources may help people to increase their spatial awareness of the soundscape environments; moreover, according to Fig. 4(j), people appear to prefer the soundscape with a little bit more spatial perception even though the feelings of boredom or liveliness for the soundscape (represented by BL, another parameter related to the overall sensation of preference) have a slight monotonically decreasing relationship with the SSP.
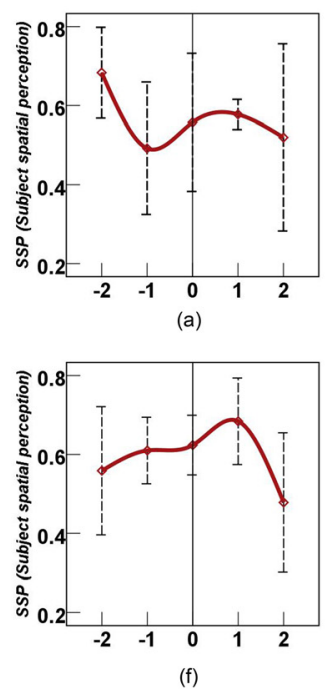
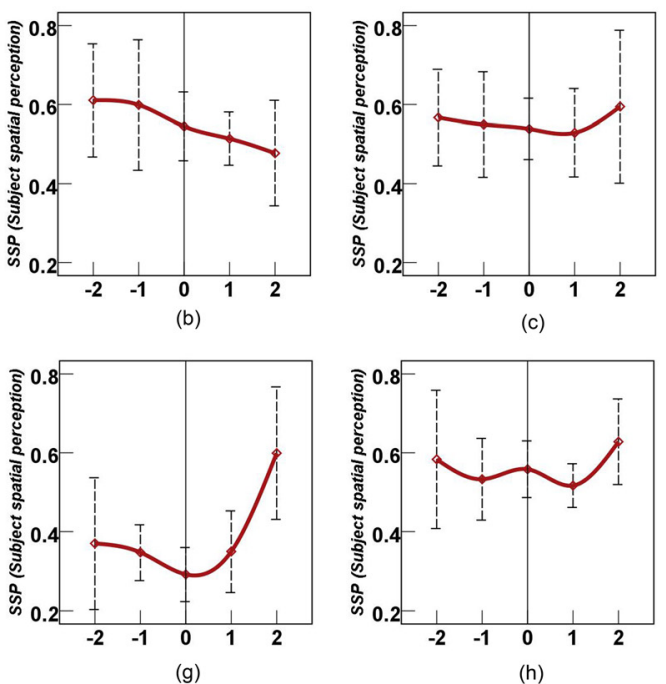

(c)

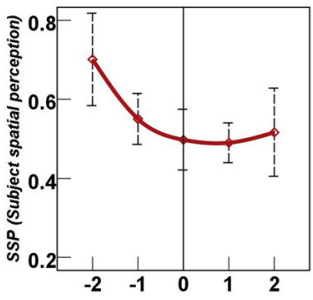

(d)

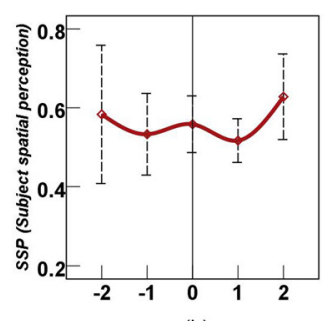

(h)

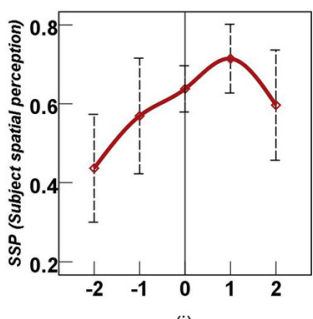

(i)

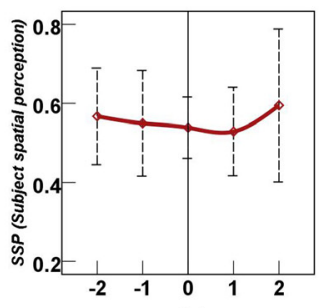

(e)

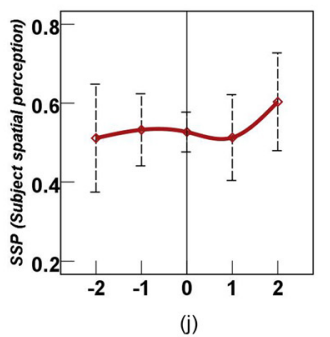

FIG. 4. (Color online) Independent effect of semantic parameters with the standard deviations (STD). (a) QN, STD =0.070, (b) BL, STD =0.057, (c) RS, $\mathrm{STD}=0.029$, (d) DO, STD $=0.087$, (e) CF, STD $=0.075$, (f) WS, STD $=0.079$, (g) SIV, STD $=0.120$, (h) TrD, STD $=0.043$, (i) NSS, STD $=0.104$, and (j) SPA, STD $=0.050$. 


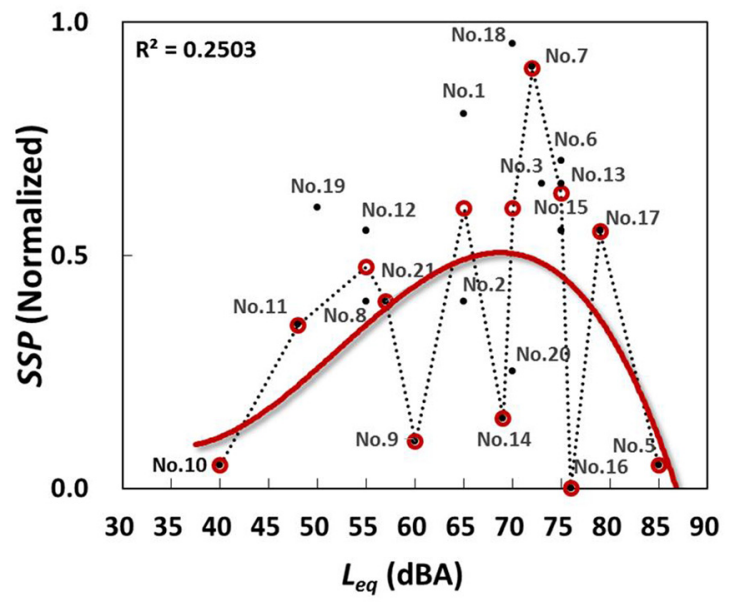

FIG. 5. (Color online) Relationship between $L_{\text {eq }}$ and SSP, with a range of moderate $L_{\text {eq }}$ values corresponding to the best SSP.

However, for the independent effects from the sensations of roughness (RS), sound intensity represented by WS, and transient dynamic ( $\mathrm{TrD}$, another parameter related to sound intensity), the situations are more complex. According to Figs. 4(c) and 4(h), both the extreme sensations of roughness and dynamic variations of sounds may slightly benefit the SSP, while on the contrary, either too much weak or strong sound may result in a slight aggression in relation to the spatial awareness, as shown in Fig. 4(f), which means that it must be an important cue to find an optimal range of sound intensity awareness for a better subjective spatial perception. This will be discussed further in Sec. III B 2, when introducing the independent effect of $L_{\mathrm{eq}}$.

\section{Effect of $L_{e q}$}

The acoustic parameter $L_{\text {eq }}$ is always a critical and positive factor for many auditory sensations of the sound environment, including loudness, noisiness, roughness, pleasance, and, of course, the spatial awareness. ${ }^{4,8}$ However, based on the results of this study, several differences are apparent: first, there is a relatively lower correlation coefficient (i.e., 0.205) between $L_{\text {eq }}$ and SSP, as listed in Table III; second, there is a range of $L_{\text {eq }}$ corresponding to the best

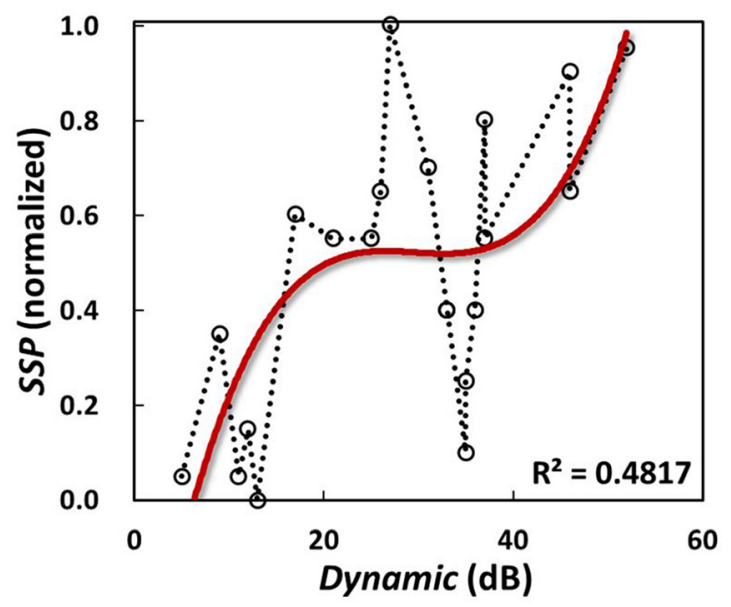

FIG. 6. (Color online) A nearly monotonically increasing relationship between dynamic $(D)$ and SSP.

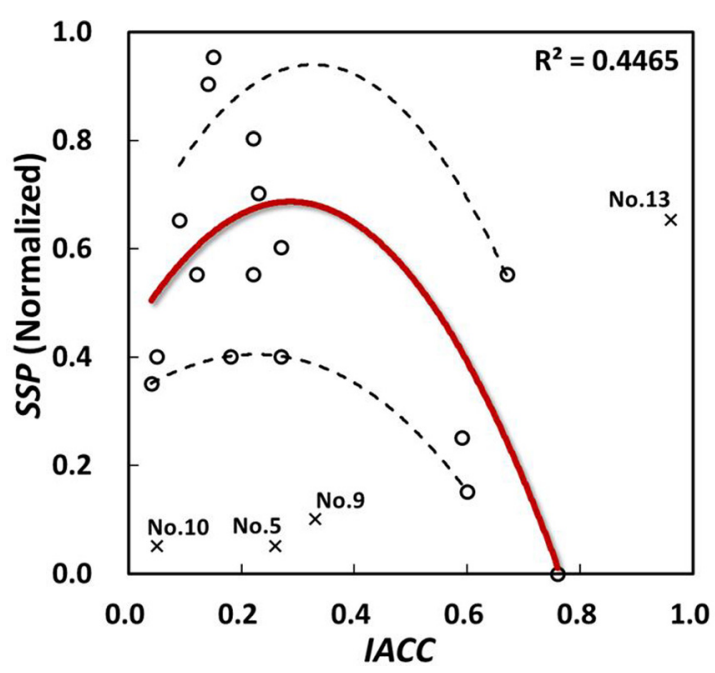

FIG. 7. (Color online) Relationship between IACC and SSP, with a range of low IACC values corresponding to the best SSP.

SSP due to the shape of the cubic polynomial fitting curve of Fig. 5. For example, sample 18 has the highest SSP value but not the highest $L_{\mathrm{eq}}$ value. This is consistent with the relationship between the parameter WS and SSP of Fig. 4(f) and contrary to the non-monotonic relationship between the parameter RS and SSP of Fig. 4(f).

According to the correlation coefficients in Table III, the sensations of noisiness (QN), roughness (RS), sound source distance (CF), weakness (WS), or variations of sound pressure levels (TrD) are highly correlated with the $L_{\text {eq }}$ values; normally, they also have similar non-monotonic relationships with the SSP. However, in addition to the parameters WS and RS, the other parameters have monotonic relationships with the SSP. Namely, the sensation for sound intensity of a real changeable soundscape environment is not exactly equal to the physical sound level.

\section{Effect of dynamic}

According to Table III, parameter $D$ has the highest positive correlation coefficient $(0.621)$ of the acoustic parameters, and its nearly monotonically increasing relationship

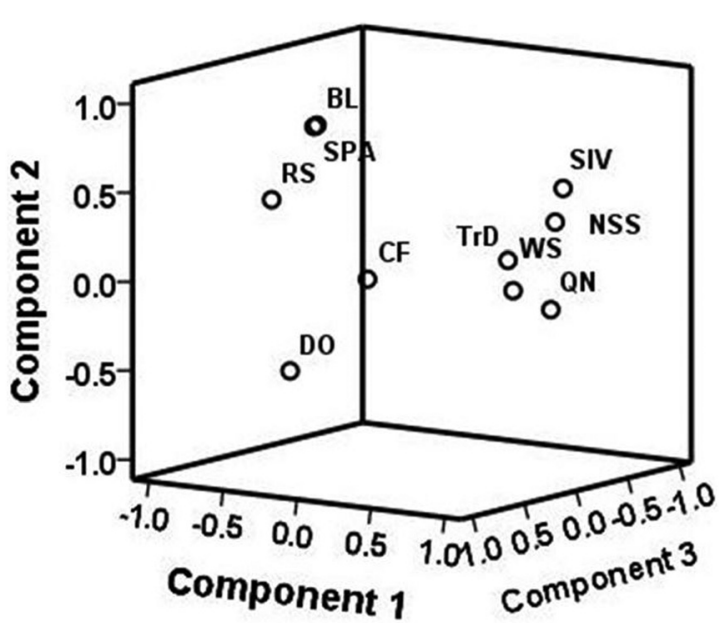

FIG. 8. Dimensions of PCA and the distributions of semantic parameters. 
TABLE IV. Results of PCA.

\begin{tabular}{lccrrr}
\hline \hline & & & \multicolumn{2}{c}{ Component coefficients $^{\mathrm{b}}$} \\
\cline { 4 - 6 } $\begin{array}{l}\text { Semantic } \\
\text { parameters }\end{array}$ & $\begin{array}{c}\text { Weight } \\
\text { order }\end{array}$ & $\begin{array}{c}\text { Total } \\
\text { weight }^{\mathrm{a}}\end{array}$ & \multicolumn{1}{c}{$\mathrm{C} 1$} & \multicolumn{1}{c}{$\mathrm{C} 2$} & \multicolumn{1}{c}{ C3 } \\
\hline QN & 4 & 0.131 & 0.391 & -0.076 & -0.008 \\
BL & 10 & 0.001 & -0.212 & 0.555 & 0.179 \\
RS & 7 & 0.106 & -0.374 & 0.229 & 0.074 \\
DO & 8 & 0.075 & -0.201 & -0.362 & 0.452 \\
CF & 3 & 0.135 & -0.301 & -0.132 & -0.552 \\
WS & 2 & 0.151 & 0.385 & 0.029 & 0.311 \\
SIV & 6 & 0.119 & 0.304 & 0.335 & -0.391 \\
TrD & 1 & 0.158 & 0.373 & 0.145 & 0.317 \\
NSS & 5 & 0.122 & 0.325 & 0.222 & -0.256 \\
SPA & 9 & 0.002 & -0.216 & 0.550 & 0.194 \\
\hline \hline
\end{tabular}

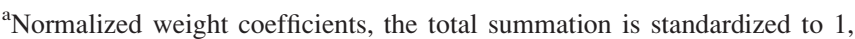
and only the first three principal components are used to calculate the total weight of each component.

${ }^{b}$ Kaiser-Meyer-Okin measure of sampling adequacy, 0.719; cumulative $90.013 \%$; extraction method, principal component analysis. The component coefficients are calculated by using component matrix values divided by the eigenroot of the corresponding principal component.

with the SSP is shown in Fig. 6. This is similar to the sensations of SIV and NSS shown in Figs. 4(g) and 4(j), respectively, but with very different from the transient dynamic sensation (TrD) shown in Fig. 4(h). Namely, the sensation for dynamic changes of a real changeable soundscape environment is not exactly equal to the physical sound dynamic.

\section{Effect of IACC}

Another important acoustic parameter related to spatial awareness is IACC, and some models based on IACC have suggested that if the value of IACC is close to zero, this means that the sounds for two ears are uncorrelated and full of spatial perceptions. On the contrary, when the sound in the middle of two ears brings identical sound pressures on both ears, then the value of IACC is 1, which indicates no sense of spatial perceptions. ${ }^{5}$ However, similar to the effect of $L_{\mathrm{eq}}$, there is a correlation coefficient of only -0.193 between IACC and the SSP, as listed in Table III, and excluding samples $5,9,10$, and 13, there is also a range of low IACC values corresponding to the best SSP, as shown in Fig. 7.

\section{Inter-relationships}

\section{Principal components and clusters}

Because the spatial awareness for soundscapes in real rural or urban environments is highly dynamic and depends significantly on multivariate sensations as mentioned above,
TABLE VI. Optimal clusters and the corresponding modes of SSP with semantic parameters.

\begin{tabular}{lcc}
\hline \hline Cluster & Mode & Semantic \\
\hline 1 & SI mode (based on the & SIV, NSS, WS, TrD, QN \\
& $\begin{array}{c}\text { parameters related to sound } \\
\text { intensity and its variations) } \\
\text { SC mode (based on the } \\
\text { parameters related to } \\
\text { sound contents) }\end{array}$ & SPA, BL, RS \\
& SD mode (based on the & \\
& parameters related & DO, CF \\
& to sound directivity) & \\
\hline
\end{tabular}

principal component analysis (PCA) and hierarchical clustering analysis (HCA) will be introduced in this section to determine some possible main components and perception models of the SSP. Setting the SSP as the controlling variable, based on the average values of the semantic parameters QN, BL, RS, DO, CF, WS, SIV, TrD, NSS, and SPA, the PCA results are shown in Fig. 8 and Table IV, with the eigenroots $[2.388,1.458,1.082]$ of the principal components vector $[C 1, C 2, C 3]$. To verify the distributions of semantic parameters, HCA results are shown in Table V. Methodologically, these two methods have a reciprocal authentication to each other, and give more confidence to extract the perception modes of SSP.

\section{Perception modes of SSP}

According to the minimum rescaled distances of some normal clustering distance algorithms in Table $\mathrm{V}$ and the effective component matrix values in Table IV, the optimal clusters and their corresponding SSP semantic modes with semantic parameters are shown in Table VI, while the Pearson clustering dendrogram is shown in Fig. 9.

Combining the HCA results of Table VI with the PCA coefficients of Table IV, it can be suggested that: the principal component $C 1$, with a total weight of 0.634 , is equivalent to the SI mode related to sound intensity and its variation and mainly dependent on the parameters SIV, NSS, WS, $\operatorname{TrD}, \mathrm{QN}$, and $L_{\mathrm{eq}} ; C 2$, with a total weight of 0.236 , is equivalent to the SC mode related to sound contents and mainly dependent on the parameters SPA, BL, and RS; and C3, with a total weight of 0.130 , is equivalent to the SD mode related to sound directivity and mainly dependent on the parameters DO, CF, and IACC. Thus, the component values of the three SSP modes can be represented by Eqs. (3)-(5), in which of the $\mathrm{SSP}_{\mathrm{SI}}, \mathrm{SSP}_{\mathrm{SC}}$, and $\mathrm{SSP}_{\mathrm{SD}}$ are defined as the new semantic components related to the perceptions of sound intensity

TABLE V. HCA results and their membership parameters.

\begin{tabular}{lcrr}
\hline \hline & & & Cluster and membership parameters \\
\cline { 2 - 5 } Clustering distance algorithm & Minimum rescaled distance & 1 & 2 \\
\hline Euclidean & 15 & SPA BL RS & DO CF \\
Pearson & 13 & SPA BL RS & SIV NSS WS TrD QN \\
Chebychev & 23 & SPA BL RS CF & DO NSS WS TrD QN \\
Minkowski & 16 & SPA BL RS & SIV NSS WS TrD QN \\
\hline \hline
\end{tabular}




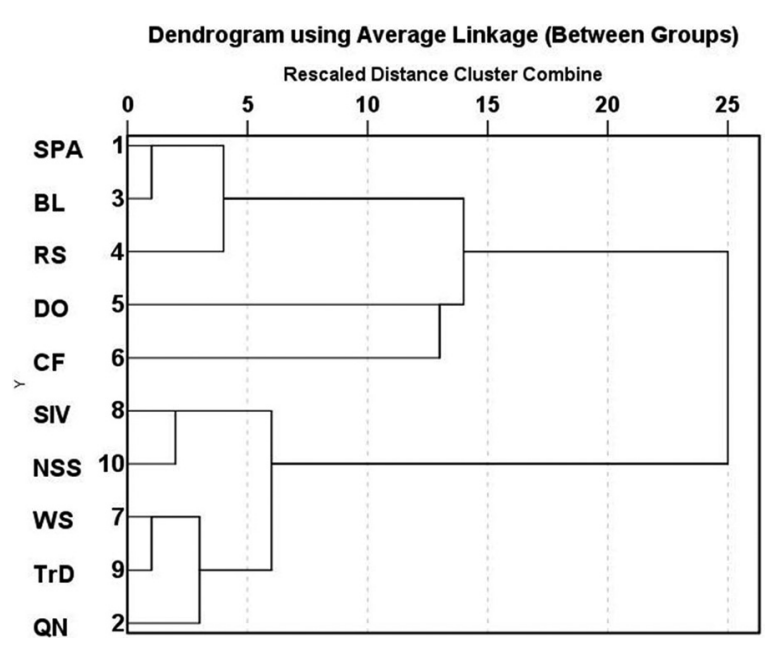

FIG. 9. HCA dendrogram of semantic parameters, Pearson correlation method.

and its variations (SI mode), sound contents (SC mode), and sound directivity (SD mode), respectively,

$$
\begin{aligned}
\mathrm{SSP}_{\mathrm{SI}} \sim \mathrm{C} 1= & 0.391 \mathrm{QN}-0.212 \mathrm{BL}-0.374 \mathrm{RS} \\
& -0.201 \mathrm{DO}-0.301 \mathrm{CF}+0.385 \mathrm{WS} \\
& +0.304 \mathrm{SIV}+0.373 \mathrm{TrD}+0.325 \mathrm{NSS} \\
& -0.216 \mathrm{SPA}, \\
\mathrm{SSP}_{\mathrm{SC}} \sim \mathrm{C} 2= & -0.076 \mathrm{QN}+0.555 \mathrm{BL}+0.229 \mathrm{RS} \\
& -0.362 \mathrm{DO}-0.132 \mathrm{CF}+0.029 \mathrm{WS} \\
& +0.335 \mathrm{SIV}+0.145 \mathrm{TrD}+0.222 \mathrm{NSS} \\
& +0.550 \mathrm{SPA}, \\
\mathrm{SSP}_{\mathrm{SI}} \sim \mathrm{C} 3= & -0.008 \mathrm{QN}+0.179 \mathrm{BL}+0.074 \mathrm{RS} \\
& +0.452 \mathrm{DO}-0.552 \mathrm{CF}+0.311 \mathrm{WS} \\
& -0.391 \mathrm{SIV}+0.317 \mathrm{TrD}-0.256 \mathrm{NSS} \\
& +0.194 \mathrm{SPA} .
\end{aligned}
$$

\section{Linear single-value evaluation model}

\section{Semantic model}

Based on the average values of Table II and Eqs. (3)-(5), values of the components $\mathrm{SSP}_{\mathrm{SI}}, \mathrm{SSP}_{\mathrm{SC}}$, and $\mathrm{SSP}_{\mathrm{SD}}$ for all samples are shown in Fig. 10.

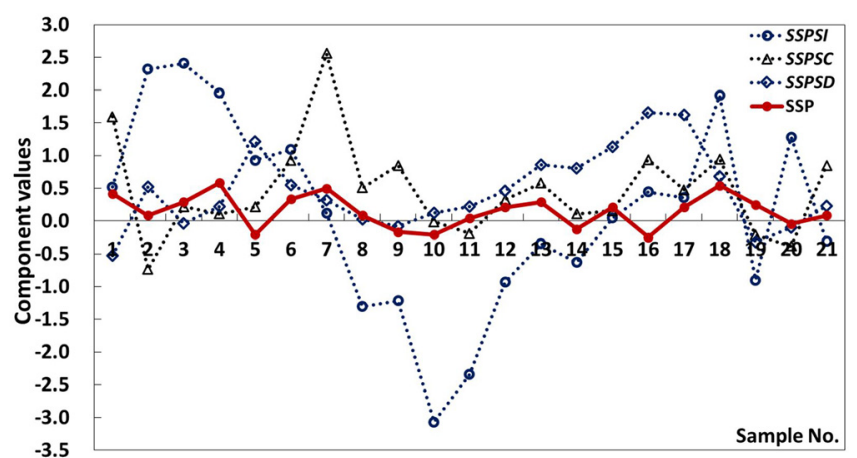

FIG. 10. (Color online) Comparisons among $\mathrm{SSP}_{\mathrm{SI}}, \mathrm{SSP}_{\mathrm{SC}}, \mathrm{SSP}_{\mathrm{SD}}$, and the SSP values of Table II.
TABLE VII. Regression among the new semantic components and SSP.

\begin{tabular}{lrrr}
\hline \hline Predictors & Coefficients & $t$ & Sig. \\
\hline (Constant) & 0.136 & 2.053 & 0.056 \\
SSP $_{\text {SI }}$ & 0.082 & 2.541 & 0.021 \\
$\mathrm{SSP}_{\mathrm{SC}}$ & 0.130 & 1.982 & 0.064 \\
$\mathrm{SSP}_{\mathrm{SD}}$ & -0.128 & -1.589 & 0.130 \\
\hline
\end{tabular}

According to the algorithm of principal components analysis, the components extracted are orthogonal to each other. Thus, a linear single-value semantic regression model of the SSP can be approximated by Eq. (6) with the multiregression coefficients in Table VII

$$
\begin{aligned}
\mathrm{SSP}= & 0.082 \cdot \mathrm{SSP}_{\mathrm{SI}}+0.130 \cdot \mathrm{SSP}_{\mathrm{SC}} \\
& -0.128 \mathrm{SSP}_{\mathrm{SD}}+0.136 .
\end{aligned}
$$

Equation (6) has already shown that the semantic parameters of evaluation are simplified to the three components corresponding to Eqs. (3), (4), and (5). If the assessments of the sensations of sound intensity, sound content and sound directivity are known, then the subjective spatial perception (SSP) of a binaural-recorded soundscape sample is easy to predict.

\section{Acoustic model}

According to linear fitting analysis, some linear regression relationships either between $L_{\mathrm{eq}}$ and $\mathrm{SSP}_{\mathrm{SI}}, D$ (dynamic), and $\mathrm{SSP}_{\mathrm{SC}}$, or IACC and $\mathrm{SSP}_{\mathrm{SD}}$ can be found in Fig. 11.

Applying the regression formulas of Fig. 11 to Eq. (6), the linear single-value semantic regression model of the $\mathrm{SSP}$, represented by the parameters $L_{\mathrm{eq}}, D$ (dynamic), and IACC, can be approximated by Eq. (7), which means that for a binaural-recorded soundscape sample, the value of the SSP can be predicted just by use its corresponding values of $L_{\mathrm{eq}}$, $D$ (dynamic), and IACC with a known awareness of sound contents

$$
\begin{aligned}
\mathrm{SSP}= & 0.082 \cdot \mathrm{SSP}_{\mathrm{SI}}+0.130 \cdot \mathrm{SSP}_{\mathrm{SC}} \\
& -0.128 \mathrm{SSP}_{\mathrm{SD}}+0.136 \\
= & 0.082\left(0.0918 \cdot L_{\mathrm{eq}}-5.9537\right) \\
& +0.130(0.0251 \cdot D-0.2344) \\
& -0.128(0.9662 \cdot \mathrm{IACC}+0.1566)+0.136 \\
= & 0.0075 \cdot L_{\mathrm{eq}}+0.0033 \cdot D \\
& -0.1237 \cdot \mathrm{IACC}+0.1055 .
\end{aligned}
$$

\section{Model test of the same set}

Based on the values of the SSP in Table II and the calculations of Eqs. (6) and (7), a test of the same set for all 21 soundscape samples was carried out to verify the effectiveness of the two evaluation models of Secs. IIID 1 and IIID2. Although the absolute value of regression coefficients are in a relatively low range $(0.082-0.136$ for the semantic model, and $0.1732-0.5235$ for the acoustic model), as the total regression Sig. value is 0.025 , these two models 

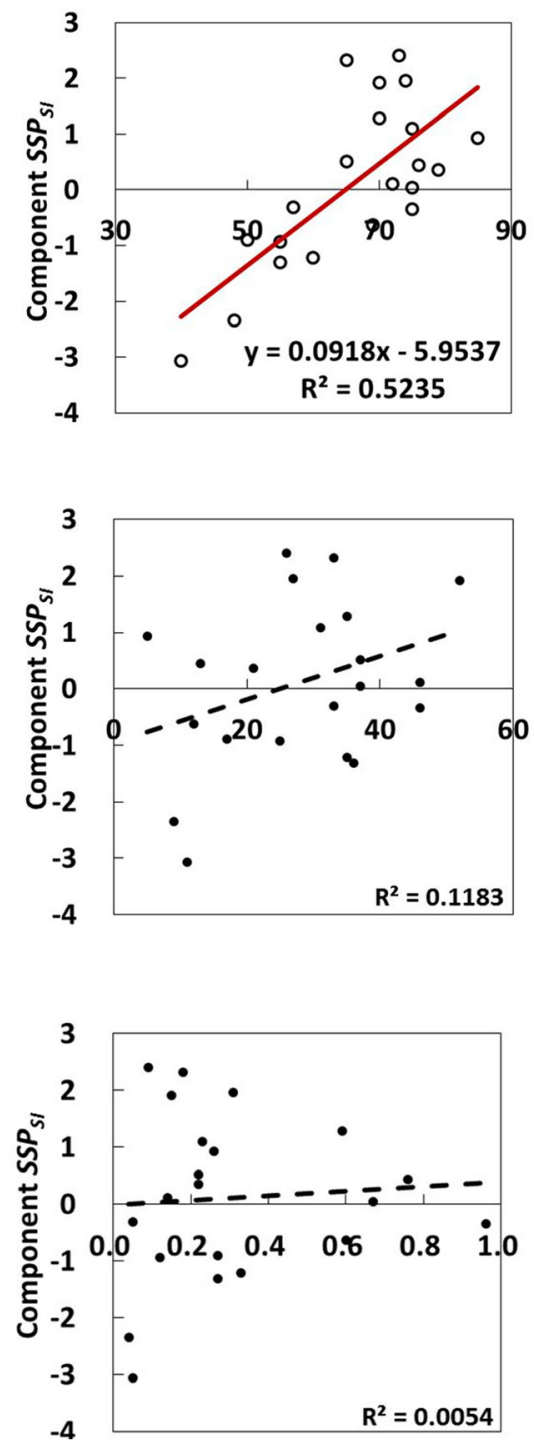

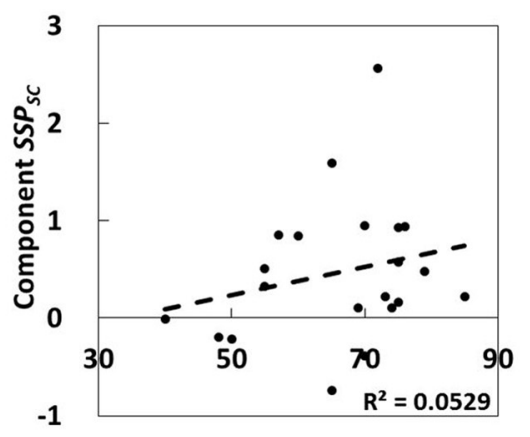

(a)

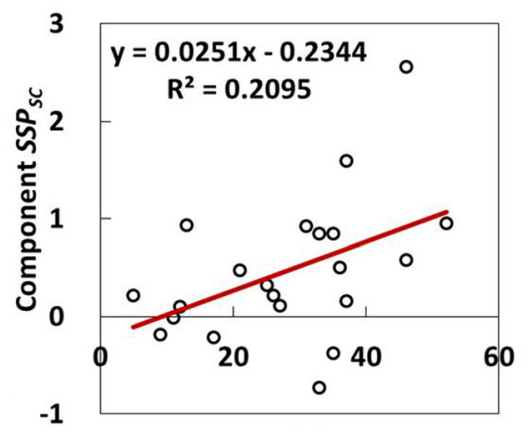

(b)

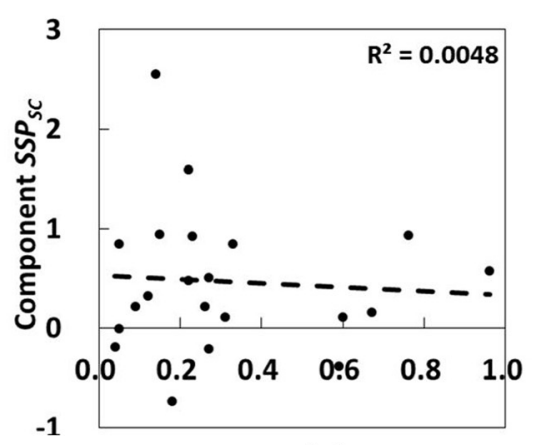

(c)
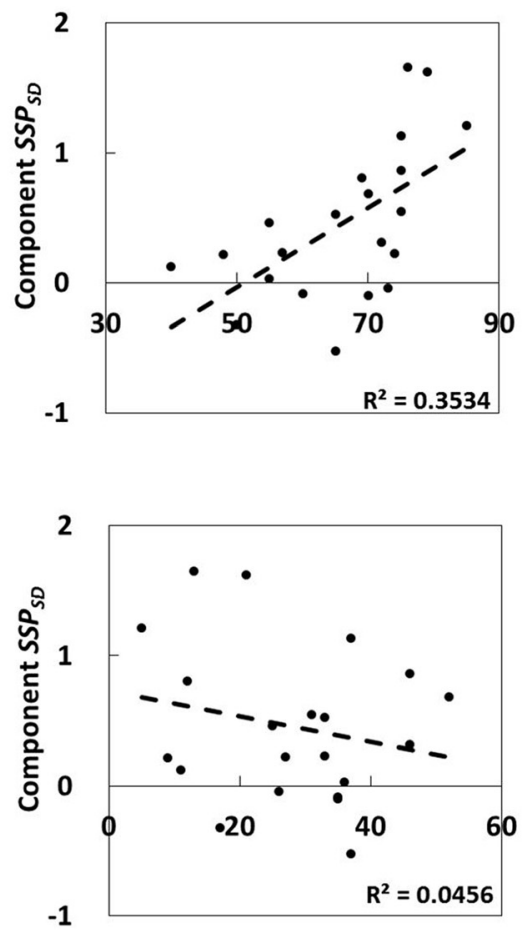

$-1$

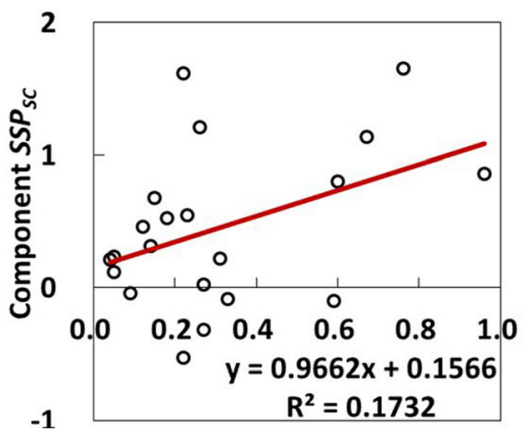

FIG. 11. (Color online) Linear relationships between semantic components and acoustic parameters, with the squared correlations and the solid lines suggesting the regression formula. (a) $L_{\mathrm{eq}}(\mathrm{dBA})$ vs $\mathrm{SSP}_{\mathrm{SI}}, \mathrm{SSP}_{\mathrm{SC}}$, and $\mathrm{SSP}_{\mathrm{SD}}$, (b) dynamic (dB) vs $\mathrm{SSP}_{\mathrm{SI}}, \mathrm{SSP}_{\mathrm{SC}}$, and SSP $\mathrm{SD}_{\mathrm{SD}}$, and (c) IACC vs SSP $\mathrm{IAC}_{\mathrm{SI}}, \mathrm{SSP}_{\mathrm{SC}}$, and $\mathrm{SSP}_{\mathrm{SD}}$.

are of statistical significance. Thus, according to the results shown in Fig. 12, both the semantic model with a correlation coefficient of 0.6438 and the acoustic model with a correlation coefficient of 0.5361 can precisely predict the trend of the values of the SSP from the auditory experiment of Sec. IIC, except for some minor differences with the exact values.

\section{CONCLUSIONS}

As discussed above, in current soundscape research efforts, many studies are focused on creating a link between acoustic parameters and psychoacoustic parameters, semantic parameters or human awareness itself and on providing an objective model to predict the corresponding subjective perception. Thus, starting from the analysis of the independent effect of 10 semantic parameters and two main acoustic parameters $L_{\mathrm{eq}}$ and IACC, the purpose of this paper was to try to reveal an evaluation model to predict the subjective spatial perception of soundscape from the above parameters.

The results of the correlation analysis and the independent effect show that the more noise (QN) an audience perceives, the less spatially aware they become, while the more closer (CF), more directional (DO), sound SIV, NSS, and dynamic $(D)$ parameters the soundscape has, the better the spatial awareness would be. Then, the sensations of roughness (RS), sound intensity (WS), transient dynamic ( $\left(\mathrm{rD}\right.$ ), and the values of $L_{\mathrm{eq}}$ and IACC have a suitable range for a better subjective spatial perception. Finally, a better spatial awareness seems to promote the preference (SPA and BL) slightly for an audience in a real soundscape environment.

In other words, according to the analysis of interrelationships among all of the parameters, the awareness of the subjective spatial perception depends on the human 


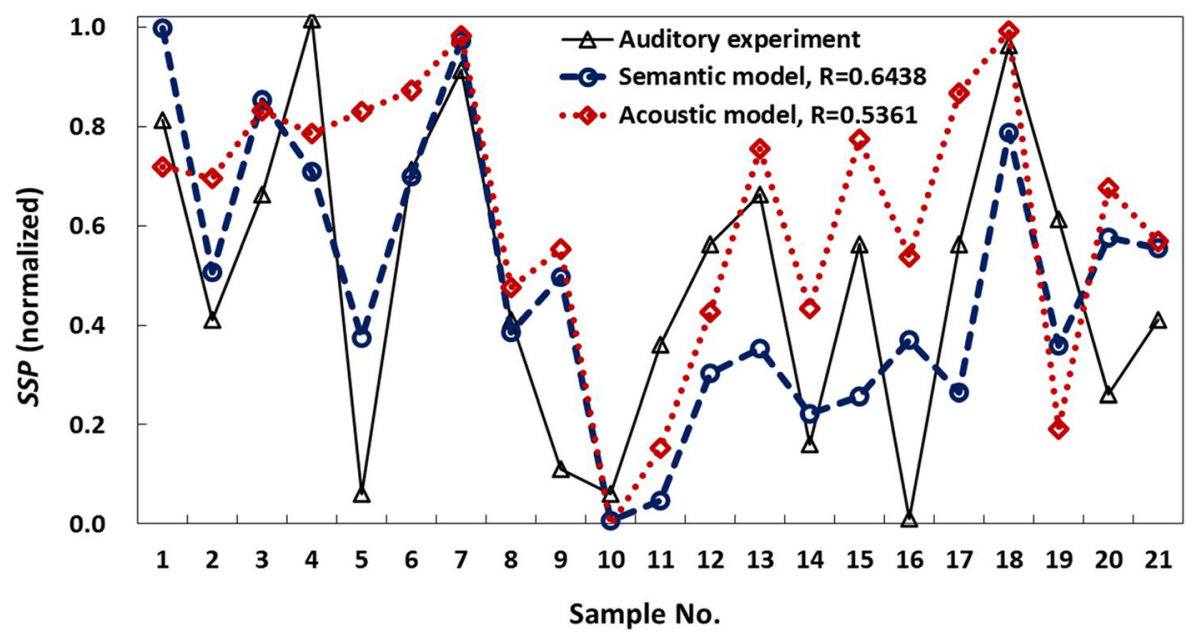

FIG. 12. (Color online) The SSP values based on the auditory experiment, semantic, and acoustic models.

sensations of sound intensity and its variations (SI mode), sound contents (SC mode), and sound directivity (SD mode). If assessments of the three sensations (the semantic components, $\mathrm{SSP}_{\mathrm{SI}}, \mathrm{SSP}_{\mathrm{SC}}$, and $\mathrm{SSP}_{\mathrm{SD}}$ ) are given in simple a 5-point Likert scale, then the SSP of a binaural-recorded soundscape sample is easy to predict by using Eq. (6), or Eq. (7) can be used to calculate the values of $L_{\text {eq }}, D$ (dynamic) and IACC with a known awareness of sound contents.

Based on the above auditory experiments, PCA and $\mathrm{HCA}$ analysis, this study suggests a $\mathrm{SSP}_{\mathrm{SI}^{-}} \mathrm{SSP}_{\mathrm{SC}}-\mathrm{SSP}_{\mathrm{SD}}$ semantic model and a $L_{\mathrm{eq}}-D$-IACC acoustic model to predict the subjective spatial perception (SSP) of a binauralrecorded soundscape sample, however, there are still any other spatial factors of the sound fields such as $W_{\text {IACC }}$ (width of the IACC or IACF), $\tau_{\text {IACC }}$ (inter-aural delay time at which the IACC is observed) and ASW (apparent source width) ${ }^{24}$ to be examined for the spatial sensations of binaural signals in the further study. But, these two models could be important for simplifying the numbers of evaluation parameters of spatial awareness and give a quantified indicator between the sound space perception and landscapes during the soundscape planning process. ${ }^{25,26}$

\section{ACKNOWLEDGMENTS}

This study is supported by the National Natural Science Foundation of China (No. 41401156), the Outstanding Training Foundation of Beijing (No. 012135407704), the "YANJING" Scholar Foundation of Beijing (No. 012155674700), and the Youth Funding Project of Humanities and Social Sciences Research Foundation from the Education Ministry of CHINA (No. 11YJCZH026). Thanks to all of the subjects from the Music College of Capital Normal University (Beijing, China), Landscape Department and School of Architecture of the University of Sheffield (Sheffield, United Kingdom). Thanks to Guowei Zhou and Wei Hua from the Music College of Guangxi Arts University (Nanning, China) for supporting the binaural recordings of all of the soundscape samples.

${ }^{1}$ R. M. Schafer, The Soundscape: Our Sonic Environment and the Tuning of the World (Knopf, New York, 1997), Introduction, pp. 15-16.
${ }^{2}$ Y. Ando, "Orthogonal Factors Describing Primary and Spatial Sensations of the Sound Field in a Concert Hall," Proceedings of the International Conference on Acoustics 2001. Rome (Sept. 2-7, 2001), available from http://www.icacommission.org/Proceedings/ICA2001Rome/paper5_07.

${ }^{3}$ B. C. Pijanowski, A. Farina, S. H. Gage, S. L. Dumyahn, and B. L. Krause, "What is soundscape ecology? An introduction and overview of an emerging new science," Landscape Ecology 26, 1213-1232 (2011).

${ }^{4}$ B. C. Pijanowski, L. J. Villanueva-Rivera, S. L. Dumyahn, A. Farina, B. L. Krause, B. M. Napoletano, S. H. Gage, and N. Peiretti, "Soundscape ecology: The science of sound in the landscape," BioScience 61(3), 203-216 (2011).

${ }^{5}$ D. Y. Ma and H. Shen, Handbook of Acoustics (Science, Beijing, 2004), Chinese edition, Chap. 20, pp. 574.

${ }^{6}$ J. Blauert, Communication Acoustics (Springer-Verlag, Berlin, 2005), Chap. 4, pp. 75-103.

${ }^{7}$ M. R. Schroeder, D. Gottlob, and K. F. Siebrasse, "Comparative study of European concert halls: Correlation of subjective preference with geometric and acoustic parameters," J. Acoust. Soc. Am. 56, 1195-1201 (1974).

${ }^{8}$ H. Fastl and E. Zwicker, Psychoacoustics: Facts and Models (SpringerVerlag, Berlin, 2007), Chap. 15, pp. 293-311.

${ }^{9}$ J. M. Potter, "On the binaural modeling of spaciousness in room acoustics," Ph.D. dissertation, Technical University of Delft, Delft, Netherlands, 1993, Introduction, pp. 1-3.

${ }^{10}$ Y. Ando, Architectural Acoustic: Blending Sound Sources, Sound Fields, and Listeners (Springer, New York, 1998), Chap. 8, pp. 120-121.

${ }^{11} \mathrm{Y}$. Ando, "A theory of primary sensations and spatial sensations measuring environmental noise," J. Sound Vib. 241(1), 3-18 (2001).

${ }^{12} \mathrm{Y}$. Ando, "Correlation factors describing primary and spatial sensations of sound fields," J. Sound Vib. 258(3), 405-417 (2002).

${ }^{13}$ B. S. Xie, X. L. Zhong, D. Rao, and Z. Q. Liang, "Head-related transfer function database and its analyses," Sci. China, Ser. G: Phys., Mech. Astron. 50(3), 267-280 (2007).

${ }^{14}$ C. Y. Zhang and B. S. Xie, "Platform for dynamic virtual auditory environment real-time rendering system," Chin. Sci. Bull. 58(3), 316-327 (2013).

${ }^{15}$ R. Shimokura, A. Cochi, L. Tronchin, and M. C. Consumi, "Calculation of IACC of any music signal convolved with impulse responses by using the interaural cross-correlation function of the sound field and the autocorrelation function of the sound source," J. South China Univ. Technol. (Natural Sci. Ed.) 35(Suppl.), 88-91 (2007).

${ }^{16}$ J. Liu, J. Kang, T. Luo, H. Behm, and T. Coppack, "Spatiotemporal variability of soundscapes in a multiple functional urban area," Landscape Urban Plann. 115, 1-9 (2013).

${ }^{17}$ J. Y. Jeon, J. Hong, and P. J. Lee, "Soundwalk approach to identify urban soundscapes individually,” J. Acoust. Soc. Am. 134(1), 803-812 (2013).

${ }^{18} \mathrm{~J}$. Hong and J. Y. Jeon, "Designing sound and visual components for enhancement of urban soundscapes," J. Acoust. Soc. Am. 134(3), 2026-2036 (2013).

${ }^{19}$ S. Dance and P. Wash, "MP3 listening levels on London Underground for music and speech," Appl. Acoust. 74(6), 850-855 (2013).

${ }^{20}$ W. Yang and J. Kang, "Acoustic comfort evaluation in urban open public spaces,” Appl. Acoust. 66, 211-229 (2005). 
${ }^{21}$ D. W. Wang, Z. Y. Deng, X. X. Li, and A. L. Liu, "Temporal features extraction for the binaural soundscape samples," Proceedings of INTERNOISE 2014, Melbourne, Australia (November 16-19, 2014), paper No. 901.

${ }^{22}$ Z. Y. Deng, D. W. Wang, A. L. Liu, H. K. Chen, and J. Zhang, "Semantic Assessment for the Soundscape of Chinese Ethnic Historical Areas," Proceedings of INTERNOISE 2013, Innsbruck, Austria (September 15-18, 2013), paper No. 0123, pp. 268.
${ }^{23}$ J. Kang and M. Zhang, "Semantic differential analysis of the soundscape in urban open public spaces," Build. Environ. 45(1), 150-157 (2010).

${ }^{24}$ Y. Ando, Auditory and Visual Sensations (Springer, New York, 2009), Chap. 7, pp. 125-136.

${ }^{25} \mathrm{X}$. Ren and J. Kang, "Effects of visual landscape factors of ecological waterscape on acoustic comfort," Appl. Acoust. 96, 171-179 (2015).

${ }^{26}$ J. Kang, "Urban soundscape," Urban Sound Environment (Taylor \& Francis Incorporating Spon, London, 2007), Chap. 3, pp. 43-106. 